\title{
Stability study of the compatibility of three chemotherapeutic agents in a mixture solution of different kinds of vehicles in the EPOCH chemotherapy scheme
}

\author{
Pengfei $\mathrm{Bi}^{1,2}$, Wen $\mathrm{Xu}^{2}$, Lei $\mathrm{Li}^{2}$, Xiangcheng $\mathrm{Li}^{2}$, Xiaoyan $\mathrm{Hu}^{2}$, Yanlei $\mathrm{Yin}^{2}$, Jing $\mathrm{Li}^{2}$ \\ ${ }^{1}$ School of Pharmacy, Qingdao University, Qingdao, China; ${ }^{2}$ Department of Pharmacy, The Affiliated Hospital of Qingdao University, Qingdao, \\ China \\ Contributions: (I) Conception and design: J Li, P Bi, W Xu; (II) Administrative support: J Li, L Li; (III) Provision of study materials or patients: P Bi, \\ W Xu, L Li; (IV) Collection and assembly of data: P Bi, X Li, Y Yin; (V) Data analysis and interpretation: P Bi, X Li, X Hu; (VI) Manuscript writing: \\ All authors; (VII) Final approval of manuscript: All authors. \\ Correspondence to: Jing Li. Department of Pharmacy, The Affiliated Hospital of Qingdao University, Qingdao 266003, China. Email: lijing7112@126.com.
}

\begin{abstract}
Background: To explore the stability of a mixture of three drugs including vindesine, etoposide, and epirubicin, assigned to infusion in an EPOCH chemotherapy regimen and provide a basis for clinical use.

Methods: After mixing the three chemotherapy drugs with $500 \mathrm{~mL}$ of $0.9 \%$ sodium chloride or $5 \%$ glucose injection, respectively, they were divided into four groups of test solution. According to the Pharmacopoeia of the People's Republic of China, 2020 Edition, injection fluid should be tested for content, osmolarity, insoluble microparticles and $\mathrm{pH}$, as well as for sterility, bacterial endotoxin and pyrogen, etc. since this experiment focuses on the compatibility of the mixture of the three drugs, sterility and the detection of bacterial endotoxin and pyrogen, etc. were not performed. The test solutions were placed at room temperature, the content was determined using high-performance liquid chromatography, and the $\mathrm{pH}$, osmolarity, and insoluble microparticle changes of the mixed solution were determined. Both imported and domestic epirubicin was used.

Results: The four groups of test solution have no significant changes in $\mathrm{pH}$, osmolarity, and insoluble microparticles were observed within $48 \mathrm{~h}$, with the contents changing by less than $5 \%$. Compared with the other three groups, the imported epirubicin saline group achieved better results with significant differences in insoluble microparticle detection items of $\geq 10$ and $\geq 25 \mu M(P<0.05)$.

Conclusions: The stability of the three drugs in $500 \mathrm{~mL} 0.9 \%$ sodium chloride and $5 \%$ glucose injection at room temperature was good. Imported epirubicin had some advantages in the number of insoluble microparticles and its $\mathrm{pH}$ was more suitable when normal saline was used as a vehicle. To reduce irritation to blood vessels by infusion, it is recommended to choose imported epirubicin with $0.9 \%$ sodium chloride mixed deployment.
\end{abstract}

Keywords: Epirubicin; etoposide; vindesine; stability; mixed solution

Submitted Aug 17, 2021. Accepted for publication Oct 16, 2021.

doi: $10.21037 /$ tcr-21-1819

View this article at: https://dx.doi.org/10.21037/tcr-21-1819

\section{Introduction}

The EPOCH protocol is the first-line treatment for patients recommended by the non-Hodgkin lymphomas NCCN guidelines and the Chinese diffuse large B-cell lymphoma diagnosis and guidelines (1). At present, the EPOCH protocol has been discussed and adopted by the hospital's Drug Administration Committee and applied in the Department of Hematology and lymphoma of our hospital. The traditional regimen was an injection of etoposide $50 \mathrm{mg} / \mathrm{m}^{2}$, doxorubicin $10 \mathrm{mg} / \mathrm{m}^{2}$, and vincristine $0.4 \mathrm{mg} / \mathrm{m}^{2}$, 
mixed with $500 \mathrm{~mL}$ of $0.9 \%$ sodium chloride slowly instilled over $24 \mathrm{~h}$ via the central vein $(2,3)$. Doxorubicin is a cell cycle nonspecific drug whose primary site of action is the nucleus, and its mechanism of action is to bind to DNA, thereby inhibiting the synthesis of nucleic acids and mitosis. Vincristine, a cell cycle specific antineoplastic drug, acts by inhibiting the polymerization of intracellular tubulin and preventing the formation of the spindle apparatus in the mitosis of proliferating cells, resulting in the arrest of cell division in the mitotic phase. Etoposide, a cell cycle specific antitumor drug, acts on DNA topoisomerase II to form a drug enzyme DNA stable reversible complex that impedes DNA repair. In vitro studies have found that these drugs are more effective at killing tumor cells at low concentrations with prolonged exposure. Several studies have confirmed (4-7) this regimen is safe, effective, and well tolerated. There are several studies that confirm the vindesine has similar antitumor activity to vincristine but has a lower incidence of neurologic adverse effects (8), so vindesine is currently used instead of vincristine. Epirubicin is doxorubicin of the isoschizomers, antitumor activity is comparable to doxorubicin but has a larger safe dose range, and less cardiotoxicity and adverse effects of myelosuppression than doxorubicin (9), so it is currently mostly used epirubicin instead of doxorubicin. However, the epirubicin specification does not recommend that the drug be mixed with other drugs for intravenous infusion. At the same time the Chinese "280 rapid search form for changes in compatibility of injection materials" and "346 rapid search form for changes in compatibility of injection materials" publications both suggest that epirubicin and vindesine are not suitable for use, and suggest that the intravenous injection of vindesine should be selected as $0.9 \%$ sodium chloride injection, while intravenous infusion (2-6 hours) should be selected as a $5 \%$ glucose injection for deployment. Although several studies have now preliminarily confirmed the compatibility stability of these three drugs (10), because in clinical practice, physicians often consider the choice of the vehicle when using it if the patients are combined with other diseases such as diabetes, renal dysfunction, etc., so whether there is a difference in the stability of these three drugs when mixed in normal saline and glucose, respectively, still needs to be verified. Besides, our hospital has prepared imported and domestic two epirubicin, and these two drugs also have differences in the manufacturing process, excipients, etc. of the drug product, while the price aspects will also affect the clinician's choice when using the EPOCH protocol, so we consider that imported and domestic varieties also need to be experimentally verified, respectively. To solve the problem of actual drug selection by clinicians in our hospital, while providing safer and rationalized medication advice and basis for clinic, we simulated the conditions under which the EPOCH protocol is clinically used to study the compatibility and stability of etoposide, vindesine, epirubicin (imported), and epirubicin (domestic) in $0.9 \%$ sodium chloride and $5 \%$ glucose, respectively, by evaluating changes of $\mathrm{pH}$, insoluble microparticles, osmolarity, and content after mixing compatibility. The results may provide a basis for the safe and effective clinical administration of these drugs.

\section{Methods}

\section{Instrument}

A Waters 2690 HPLC instrument (Waters, USA), ultrapure water (Millipore, USA), electronic balance, $\mathrm{pH}$ meter (Diamagnetic, phs-3c), insoluble microparticle detector (GFW-5JA, Tianhe Medical Instrument Co., Ltd.), and osmolality measurement (SMC 30C, Tianjin Sgray Technology Co., Ltd.) were used in this study.

\section{Trial medication}

The following medication was used: etoposide injection (Jiangsu Hengrui Medicine Co., Ltd, specification: $5 \mathrm{~mL}$ : $0.1 \mathrm{~g}$, lot No.170421BJ); epirubicin hydrochloride for injection (imported) (famaxine, FMX, Pfizer Pharmaceutical Ltd, specification $10 \mathrm{mg}$, lot No. R29762); epirubicin hydrochloride for injection (domestic) (Ai Dasheng, ADS, Zhejiang Hisun Pharmaceutical Co., Ltd., specification $10 \mathrm{mg}$, lot No. 17006321); vindesine sulfate for injection (Hangzhou Minsheng Pharmaceutical Co., Ltd., specification $1 \mathrm{mg}$, lot No. 170506D); etoposide control (Chinese Academy for food and drug control, lot No.100388); epirubicin hydrochloride control (Chinese Academy for food and drug control, lot No.130560); vindesine sulfate control (Chinese Academy for food and drug control, lot No.100454). 0.9\% sodium chloride injection $500 \mathrm{~mL}$, Qingdao Huaren Pharmaceutical Co., Ltd., lot No. G1707043; 5\% glucose injection $500 \mathrm{~mL}$, Qingdao Huaren Pharmaceutical Co., Ltd., lot No. E1707047. formic acid (analytical grade), acetonitrile, and methanol were used as chromatographically pure reagents. 


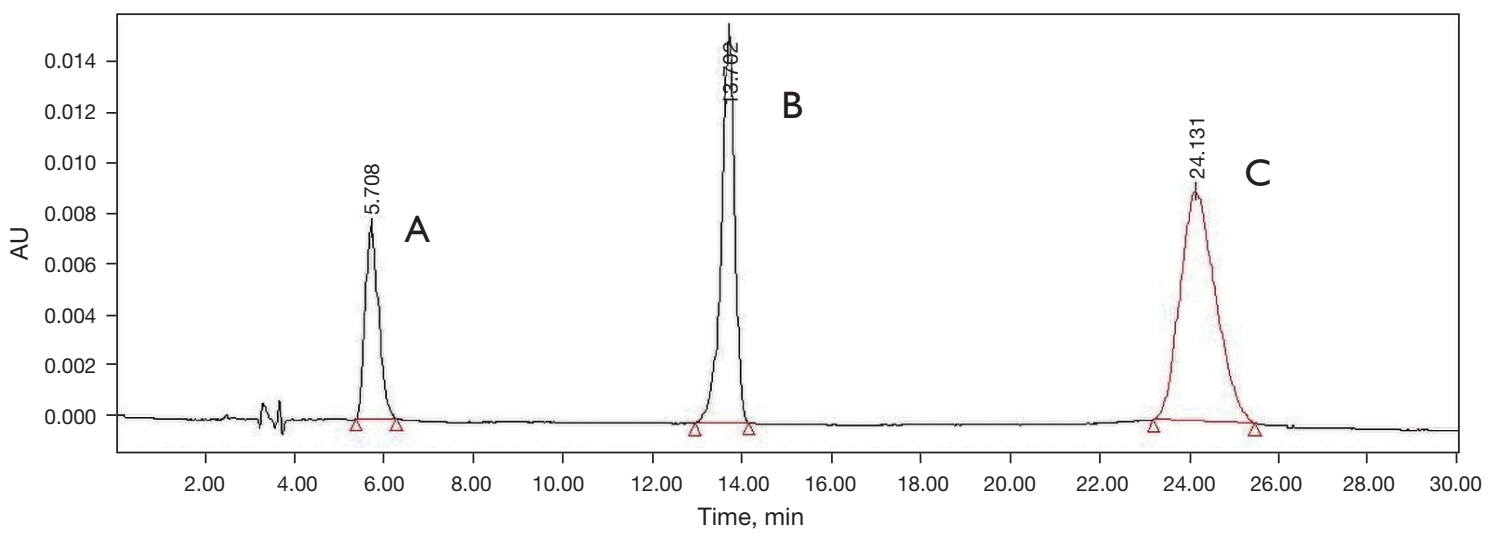

Figure 1 Chromatogram of sample solution. A: vindesine, B: etoposide, C: epirubicin.

\section{Study methods and conditions}

\section{Chromatographic conditions}

The following conditions applied: Column: Venus ASB $\mathrm{C}_{18}(4.6 \mathrm{~mm} \times 250 \mathrm{~mm}, 5 \mu \mathrm{m})$; mobile phase: $0.5 \%$ formic acid: methanol: acetonitrile $(60: 25: 15, \mathrm{v} / \mathrm{v})$; flow rate: $1.0 \mathrm{~mL} \cdot \mathrm{min}^{-1}$; column temperature: room temperature, $25^{\circ} \mathrm{C}$; detection wavelength: $254 \mathrm{~nm}$; injection volume: $10 \mu \mathrm{L}$. Chromatograms are shown in Figure 1.

\section{Preparation of solutions Reference solution}

Etoposide $25 \mathrm{mg}$ was accurately weighed and placed into a $25 \mathrm{~mL}$ volumetric flask, dissolved in methanol, and brought to volume as an etoposide control stock solution $(1,000 \mu \mathrm{g} / \mathrm{mL})$. Epirubicin $15 \mathrm{mg}$ was then accurately weighted and placed in a $25 \mathrm{~mL}$ volumetric flask, dissolved in methanol, and brought to volume as an the epirubicin control stock solution $(600 \mu \mathrm{g} / \mathrm{mL})$.

\section{Test solution}

According to the clinical dosage (etoposide $50 \mathrm{mg} / \mathrm{m}^{2}$, epirubicin $30 \mathrm{mg} / \mathrm{m}^{2}$, and vindesine $1 \mathrm{mg} / \mathrm{m}^{2}$ ), the body surface area was calculated as $1.75 \mathrm{~m}^{2}$, and etoposide injection $4.20 \mathrm{~mL}$, epirubicin hydrochloride (domestic) and epirubicin hydrochloride (imported) $50 \mathrm{mg}$, and vindesine sulfate $1.65 \mathrm{mg}$ were obtained. Etoposide, epirubicin (imported), and vindesine were added to $500 \mathrm{~mL}$ of $0.9 \%$ sodium chloride injection and $5 \%$ glucose injection as N-FMX and G-FMX, respectively; etoposide, epirubicin (homemade), and vindesine were added to $500 \mathrm{~mL}$ of $0.9 \%$ sodium chloride injection and $5 \%$ glucose injection into test $\mathrm{N}$-ADS and test G-ADS, respectively, and the four aliquots were placed at room temperature $\left(25^{\circ} \mathrm{C}\right)$.

\section{Preparation of standard curves}

An appropriate amount of etoposide control stock solution was taken and formulated into serial mass concentration control solutions containing etoposide 50, 100, 200, 500, and $1,000 \mu \mathrm{g} / \mathrm{mL}$, respectively, and measured by injection under the chromatographic conditions described above. Peak area values $(\mathrm{A})$ versus mass concentrations $(\mathrm{C}, \mu \mathrm{g} / \mathrm{mL})$ were subjected to linear regression to obtain a standard curve for etoposide as $\mathrm{A}=4194.2 \mathrm{C}-1669.9, \mathrm{R}^{2}=0.9997$, and the results showed a good linear relationship of etoposide in the range of $50-1,000 \mu \mathrm{g} / \mathrm{mL}$, respectively, which were injected and determined according to the chromatographic conditions described above. Peak area values (A) versus mass concentrations $(\mathrm{C}, \mu \mathrm{g} / \mathrm{mL})$ were subjected to linear regression, and the standard curve of vindesine was obtained as $\mathrm{A}=52742 \mathrm{C}+3727.8, \mathrm{R}^{2}=0.9999$. The results showed good linearity for vindesine in the range of $1-20 \mu \mathrm{g} / \mathrm{mL}$.

Appropriate amounts of the stock solution of epirubicin were taken and formulated into serial mass concentration control solutions containing epirubicin 30, 60, 120, 300, and $600 \mu \mathrm{g} / \mathrm{mL}$ ) were subjected to linear regression and the standard curve of epirubicin was obtained as $\mathrm{A}=$ $21320 C+6996.3, R^{2}=0.9999$. The results showed a good linear relationship between epirubicin in the range of $30-600 \mu \mathrm{g} / \mathrm{mL}$.

\section{Limit of quantitation}

An appropriate amount of the lowest concentration solution under the linear term was taken and diluted stepwise with the mobile phase to determine the limits of quantification as $0.2 \mu \mathrm{g} / \mathrm{mL}$ for etoposide, $0.1 \mu \mathrm{g} / \mathrm{mL}$ for epirubicin at a signal-to-noise ratio of approximately 10 . 
Table 1 Rate of recovery $(\mathrm{n}=6, \%)$

\begin{tabular}{lccc}
\hline \multirow{2}{*}{ Loading volume } & \multicolumn{3}{c}{ Rate of recovery, \% } \\
\cline { 2 - 4 } & Vindesine & Etoposide & Epirubicin \\
\hline $40 \%$ & 98.2 & 100.6 & 100.3 \\
& 101.1 & 101.1 & 99.8 \\
\multirow{2}{*}{$50 \%$} & 99.3 & 100.6 & 98.8 \\
& 101.2 & 100.2 & 99.8 \\
& 100.1 & 99.8 & 100.5 \\
$60 \%$ & 98.6 & 98.2 & 98.5 \\
& 100.2 & 99.4 & 99.2 \\
& 99.6 & 100.1 & 101.8 \\
Average value & 99.7 & 99.9 & 99.7 \\
\hline
\end{tabular}

\section{Precision}

The middle concentration solution under the linear term was taken and the injection was repeated six times under the above chromatographic conditions. The peak areas of the three drugs were recorded to calculate the injection precision and the results showed etoposide $0.25 \%$, vindesine $0.66 \%$, and epirubicin $0.26 \%$.

\section{Rate of recovery}

Stock solutions with known concentrations were added to etoposide solution, formulated to contain $40 \%, 50 \%$, and $60 \%$ etoposide in three portions each, measured under the chromatographic conditions described above, and the peak areas of etoposide were recorded, and the recoveries were calculated. The recoveries of vindesine and epirubicin were determined by the same method, and the results are shown in Table 1, indicating good repeatability.

\section{Content assay}

According to the common clinical volume and used concentration, the four groups of the compatibility mixed drug solution of "Test solution" above were respectively sampled at different times after addition $(0,2,4,6,8,10$, $12,24,36,48 \mathrm{~h}$ ) for the content determination of the three drugs. The appearance traits of the drug solution were then observed to see the specific results with or without discoloration or impurity.
PH, osmolarity, and insoluble microparticle assay

The $\mathrm{pH}$, osmolarity, and insoluble microparticles of the test solution were measured at $0,2,4,6,8,10,12,24,36$, and $48 \mathrm{~h}$ after mixing the four groups of the compatibility mixture under "Test solution" above.

\section{Statistics}

SPSS17.0 software was used to analyze the experimental results and calculate the mean, standard deviation of the percentage contents, $\mathrm{pH}$, osmolarity, and insoluble microparticles of each component, respectively. One way ANOVA was used to compare various data among samples from the four groups, and the LSD method was further selected for pairwise comparison according to the homogeneity of variance test, with the significance level set as $\alpha=0.05$.

\section{Results}

\section{Content assay results}

The results of the test showed that within $48 \mathrm{~h}$, the mixed drugs of the four compatibility groups had no color change in appearance and no impurities were produced. The content changes were in the range of $\pm 5 \%$ or less, which was within the effective range of clinical medication (Table 2), and the chromatogram at $48 \mathrm{~h}$ showed no other absorption peaks.

\section{PH, osmolality, insoluble microparticle assay results}

The test results showed (Table 3) there was no obvious change in the $\mathrm{pH}$ and osmotic pressure of the mixed drug solutions of the four groups within $48 \mathrm{~h}$, and the change of insoluble microparticles did not exceed the requirements of the 2020 edition of Pharmacopoeia of the People's Republic of China, which is $10 \mu \mathrm{m}$ or more particles no more than 25 per $\mathrm{mL}$, and $25 \mu \mathrm{m}$ or more particles no more than 3 particles per $\mathrm{mL}$.

\section{Statistical results}

The results showed that there were no significant differences in the contents of the three drugs among the four groups within $48 \mathrm{~h}$ after the deployment of the infusion $(\mathrm{P}>0.05)$. The different vehicle groups were compared, and significant differences $(\mathrm{P}<0.05)$ were observed between saline $(\mathrm{N}-\mathrm{FMX}$ 
Table 2 Changes in the content of vindesine, etoposide, and epirubicin in a compatible solution $(\mathrm{n}=3, \bar{x} \pm \mathrm{s})$

\begin{tabular}{|c|c|c|c|c|}
\hline \multirow{2}{*}{ Solution } & \multirow{2}{*}{ Time/h } & \multicolumn{3}{|c|}{ Content, $\%(x \pm s)$} \\
\hline & & Vindesine & Etoposide & Epirubicin \\
\hline \multirow[t]{10}{*}{ N-FMX } & 0 & $100.00 \pm 0.00$ & $100.00 \pm 0.00$ & $100.00 \pm 0.00$ \\
\hline & 2 & $100.18 \pm 0.22$ & $100.44 \pm 0.76$ & $100.75 \pm 0.85$ \\
\hline & 4 & $100.02 \pm 0.04$ & $100.04 \pm 0.41$ & $100.33 \pm 0.57$ \\
\hline & 6 & $99.60 \pm 0.88$ & $99.74 \pm 0.64$ & $99.86 \pm 0.64$ \\
\hline & 8 & $99.35 \pm 0.23$ & $100.49 \pm 0.59$ & $100.08 \pm 0.09$ \\
\hline & 10 & $99.04 \pm 0.04$ & $99.92 \pm 0.65$ & $100.58 \pm 0.58$ \\
\hline & 12 & $98.96 \pm 0.22$ & $100.04 \pm 0.02$ & $100.14 \pm 0.09$ \\
\hline & 24 & $98.96 \pm 0.07$ & $100.14 \pm 0.69$ & $99.98 \pm 0.70$ \\
\hline & 36 & $99.15 \pm 0.61$ & $100.06 \pm 0.02$ & $100.11 \pm 0.81$ \\
\hline & 48 & $98.73 \pm 0.35$ & $100.22 \pm 0.94$ & $100.05 \pm 0.94$ \\
\hline \multirow[t]{10}{*}{ N-ADS } & 0 & $100.00 \pm 0.00$ & $100.00 \pm 0.00$ & $100.00 \pm 0.00$ \\
\hline & 2 & $99.80 \pm 0.12$ & $99.86 \pm 0.53$ & $100.01 \pm 0.37$ \\
\hline & 4 & $99.22 \pm 0.85$ & $100.03 \pm 0.11$ & $100.03 \pm 0.89$ \\
\hline & 6 & $99.08 \pm 0.88$ & $99.97 \pm 0.33$ & $99.75 \pm 0.29$ \\
\hline & 8 & $99.67 \pm 0.43$ & $100.04 \pm 0.38$ & $100.06 \pm 0.69$ \\
\hline & 10 & $99.09 \pm 0.11$ & $99.82 \pm 0.68$ & $100.09 \pm 0.45$ \\
\hline & 12 & $98.81 \pm 0.45$ & $99.74 \pm 0.18$ & $99.99 \pm 0.19$ \\
\hline & 24 & $98.74 \pm 0.25$ & $99.41 \pm 0.39$ & $99.41 \pm 0.32$ \\
\hline & 36 & $98.60 \pm 0.38$ & $100.00 \pm 0.28$ & $99.67 \pm 0.22$ \\
\hline & 48 & $98.34 \pm 0.63$ & $99.76 \pm 0.63$ & $99.89 \pm 0.63$ \\
\hline \multirow[t]{10}{*}{ G-FMX } & 0 & $100.00 \pm 0.00$ & $100.00 \pm 0.00$ & $100.00 \pm 0.00$ \\
\hline & 2 & $100.56 \pm 0.96$ & $100.37 \pm 0.31$ & $100.54 \pm 0.41$ \\
\hline & 4 & $100.43 \pm 0.83$ & $100.31 \pm 0.27$ & $100.37 \pm 0.19$ \\
\hline & 6 & $99.35 \pm 0.30$ & $100.24 \pm 0.64$ & $99.67 \pm 0.29$ \\
\hline & 8 & $99.26 \pm 0.29$ & $100.10 \pm 0.19$ & $100.22 \pm 0.47$ \\
\hline & 10 & $98.90 \pm 0.44$ & $99.89 \pm 0.74$ & $99.66 \pm 0.81$ \\
\hline & 12 & $99.01 \pm 0.59$ & $100.03 \pm 0.24$ & $99.94 \pm 0.05$ \\
\hline & 24 & $98.87 \pm 0.20$ & $100.29 \pm 0.74$ & $99.66 \pm 0.59$ \\
\hline & 36 & $98.87 \pm 0.39$ & $100.24 \pm 0.59$ & $99.67 \pm 0.73$ \\
\hline & 48 & $98.26 \pm 0.43$ & $100.12 \pm 0.57$ & $99.99 \pm 0.20$ \\
\hline
\end{tabular}

Table 2 (continued)
Table 2 (continued)

\begin{tabular}{ccccc}
\hline \multirow{2}{*}{ Solution } & \multirow{2}{*}{ Time/h } & \multicolumn{3}{c}{ Content, \% $(x \pm s)$} \\
\cline { 3 - 5 } & & Vindesine & Etoposide & Epirubicin \\
\hline G-ADS & 0 & $100.00 \pm 0.00$ & $100.00 \pm 0.00$ & $100.00 \pm 0.00$ \\
& 2 & $99.99 \pm 0.82$ & $99.93 \pm 0.05$ & $99.81 \pm 0.04$ \\
& 4 & $99.28 \pm 0.34$ & $99.86 \pm 0.13$ & $99.40 \pm 0.36$ \\
& 6 & $98.82 \pm 0.25$ & $99.21 \pm 0.36$ & $99.21 \pm 0.57$ \\
& 8 & $99.70 \pm 0.50$ & $99.94 \pm 0.69$ & $99.24 \pm 0.03$ \\
& 10 & $99.10 \pm 0.40$ & $99.74 \pm 0.75$ & $99.74 \pm 0.37$ \\
& 12 & $99.08 \pm 0.68$ & $99.89 \pm 0.11$ & $99.89 \pm 0.16$ \\
& 24 & $98.72 \pm 0.12$ & $99.84 \pm 0.51$ & $99.84 \pm 0.91$ \\
& 48 & $98.14 \pm 0.71$ & $99.95 \pm 0.51$ & $99.95 \pm 0.90$ \\
& $98.58 \pm 0.37$ & $100.33 \pm 0.78$ & $100.12 \pm 0.34$ \\
\hline
\end{tabular}

$\mathrm{N}-\mathrm{FMX}$, imported epirubicin, vindesine, and etoposide in $0.9 \%$ sodium chloride injection; N-ADS, locally made epirubicin, vindesine, and etoposide in $0.9 \%$ sodium chloride injection; G-FMX, imported epirubicin, vindesine, and etoposide in 5\% glucose injection; G-ADS, locally made epirubicin, vindesine, and etoposide in $5 \%$ glucose injection.

and N-ADS) and glucose groups (G-FMX and G-ADS) in $\mathrm{pH}$ and osmolarity results. In terms of insoluble microparticles, at hour 0 , four groups with $\geq 10 \mu \mathrm{m}(\mathrm{P}=0.848)$ and $\geq 25 \mu \mathrm{m}(\mathrm{P}=0.330)$ did not significantly differ in the number of microparticles. However, with longer placement time, at $\geq 10 \mu \mathrm{m}$, the number of microparticles $(17.9 \pm 1.1)$ of the N-FMX group compared with the other three groups of N-ADS (23.5 \pm 0.6$)$, G-FMX $(21.1 \pm 1.3)$, and G-ADS $(21.7 \pm 1.3)$ were significantly different $(\mathrm{P}=0.000,0.013,0.000$, respectively), and at $\geq 25 \mu \mathrm{m}$ of particles $(0.3 \pm 0.1)$ compared with the other three groups of N-ADS $(1.2 \pm 0.2)$, G-FMX $(0.9 \pm 0.3)$, and G-ADS $(0.8 \pm 0.2)$ were similarly significant $(\mathrm{P}=0.001,0.009$, and 0.029 , respectively).

\section{Discussion}

\section{Selection of chromatographic conditions}

Chromatographic conditions for the mobile phase of etoposide, epirubicin, and vindesine were selected with 
Table 3 Changes in $\mathrm{pH}$, osmotic pressure, and insoluble particles in compatible solutions $(\mathrm{n}=3, \bar{x} \pm \mathrm{s})$

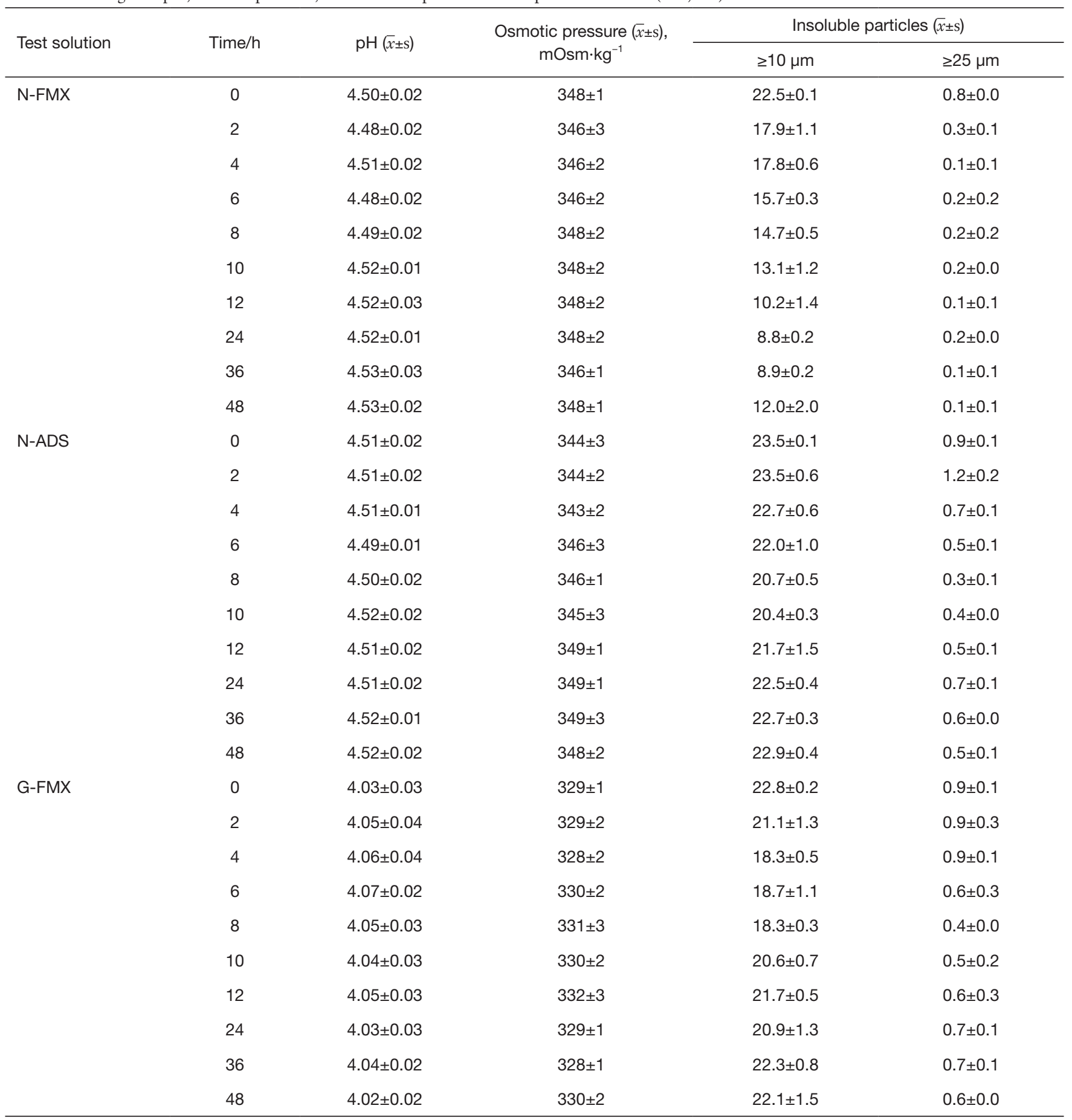

Table 3 (continued) 
Table 3 (continued)

\begin{tabular}{|c|c|c|c|c|c|}
\hline Test solution & Time/h & $\mathrm{pH}(x \pm \mathrm{s})$ & $\begin{array}{l}\text { Osmotic pressure }(x \pm s) \\
\qquad \mathrm{mOsm} \cdot \mathrm{kg}^{-1}\end{array}$ & \multicolumn{2}{|c|}{ Insoluble particles $(\bar{x} \pm s)$} \\
\hline \multirow[t]{7}{*}{ G-ADS } & 0 & $4.00 \pm 0.01$ & $330 \pm 2$ & $23.6 \pm 0.2$ & $1.0 \pm 0.2$ \\
\hline & 2 & $4.05 \pm 0.04$ & $328 \pm 1$ & $21.7 \pm 1.3$ & $0.8 \pm 0.2$ \\
\hline & 4 & $4.04 \pm 0.03$ & $332 \pm 3$ & $22.1 \pm 0.2$ & $0.7 \pm 0.1$ \\
\hline & 8 & $4.04 \pm 0.02$ & $333 \pm 2$ & $19.3 \pm 0.6$ & $0.3 \pm 0.3$ \\
\hline & 10 & $4.02 \pm 0.02$ & $333 \pm 2$ & $21.7 \pm 1.3$ & $0.3 \pm 0.1$ \\
\hline & 12 & $4.03 \pm 0.02$ & $330 \pm 3$ & $22.2 \pm 0.3$ & $0.3 \pm 0.1$ \\
\hline & 24 & $4.02 \pm 0.02$ & $331 \pm 2$ & $21.6 \pm 1.2$ & $0.5 \pm 0.1$ \\
\hline
\end{tabular}

N-FMX, imported epirubicin, vindesine, and etoposide in $0.9 \%$ sodium chloride injection; N-ADS, locally made epirubicin, vindesine, and etoposide in $0.9 \%$ sodium chloride injection; G-FMX, imported epirubicin, vindesine, and etoposide in 5\% glucose injection; G-ADS, locally made epirubicin, vindesine, and etoposide in $5 \%$ glucose injection.

reference to the 2020 edition of Pharmacopoeia of the People's Republic of China and other studies, most of which mentioned the use of phosphate buffer as an integral part of the mobile phase under the condition of the $\mathrm{C}_{18}$ column. However, as this experiment mimicked the impurities in the liquid-mass combination deployment solution analyzed in the future, the nonvolatile phosphate buffer was not selected as the aqueous phase. A review of the literature found that the lower the $\mathrm{pH}$ of the mobile phase, the better the separation of the three, so a formic acid dilution commonly used in chromatographic conditions was chosen to lower the $\mathrm{pH}$ of the mobile phase. Following the concentration of formic acid from low to high injection, it was found that the vindesine retention time was around $5 \mathrm{~min}$ when $0.5 \%$ formic acid was used, and there was no other heterogenous peak interference in the peak region. Adjusting the ratio of methanol to acetonitrile showed etoposide produced an overlap in retention time with epirubicin when the ratio of methanol was too low, while increasing the methanol ratio and decreasing the acetonitrile ratio improved the resolution of the two. The experimental mobile phase was finally determined to be $0.5 \%$ formic acid: methanol: acetonitrile $(60: 25: 15, \mathrm{v} / \mathrm{v})$, with a flow rate $1.0 \mathrm{~mL} \cdot \mathrm{min}^{-1}$; column temperature: room temperature, $25^{\circ} \mathrm{C}$; and detection wavelength: $254 \mathrm{~nm}$. Under these conditions, vindesine, etoposide, and epirubicin showed peaks at 5.7, 13.7, and $24.1 \mathrm{~min}$, respectively, which did not interfere with each other.

\section{Choice of vehicle for sample solution}

Since the concentrations of each component of the sample solution were in the linear range, they could be directly injected for detection, and the results showed there was no statistical difference in the changes of the contents of the three drugs, whether in saline or glucose.

As no significant changes in content were observed between samples, we focused on the safety of infusion use. Osmolality can influence the movement of water molecules in cells of the vessel wall, and the higher the osmolality, the greater the venous irritation (11). Hypertonic solutions (>340 $\mathrm{mOsm} / \mathrm{L}$ ), which dehydrate the vessel intima, cause damage to the intima by exposing the intima to irritant solutions, resulting in phlebitis, venospasm, and thrombosis. In this experiment, the osmolality of the mixed solution saline group was greater than that of the glucose group (all time periods were statistically different, $\mathrm{P}<0.05$ ), and the measured results at each time were slightly higher than $340 \mathrm{mOsm} / \mathrm{L}$. Extensive research in this country and abroad has been conducted on how to reduce the phlebitis caused by the irritation of injectable agents, and results have shown that the $\mathrm{pH}$ range of tolerable infusion for humans is 4-9, and a $\mathrm{pH}$ value below 4 or above 9 will lead to pain and phlebitis. Further, the severity of phlebitis is directly related 
to the $\mathrm{pH}$ of infusion, and the lower the $\mathrm{pH}$ value, the more serious the phlebitis. In this study, the $\mathrm{pH}$ of the dextrose group was smaller (all time periods were statistically different, $\mathrm{P}<0.05$ ) and closer to 4.00 than that of the saline group, which is close to the human tolerable $\mathrm{pH}$ minimum for infusion. Comparing the $\mathrm{pH}$ and osmolality of the saline and glucose groups showed there were pros and cons to using the two vehicle configurations of mixed infusion. While there were some statistical differences, considering this treatment regimen has a longer instillation time $(\sim 48 \mathrm{~h})$ and slower instillation rate, the effects of lower $\mathrm{pH}$ and higher osmolality on blood vessels were of little clinical significance between groups.

Insoluble microparticles are particulate impurities in infusion fluid which widely exist in infusion products, and are an important factor leading to adverse reactions/events in intravenous administration. Insoluble microparticles in an infusion are macroscopically invisible nonmetabolic particulate impurities that are typically less than $50 \mu \mathrm{m}$ and can cause immediate or long-term hazards to the human body. When deployment was just completed in this experiment, insoluble microparticles of the four groups did not differ significantly due to incomplete mixing of the drug with the system of diluted solutions, but all were close to the upper limit of the prescribed range of pharmacopoeias. Whereas there were fewer insoluble microparticles in the group that imported epirubicin in saline with progressively longer placement time, they were less affected by the time variation. After the time of placement reached $2 \mathrm{~h}$, $\geq 10$ and $\geq 25 \mu \mathrm{M}$ of the microparticle number of the other three compatibility solutions (N-ADS, G-FMX, G-ADS) were significantly different $(\mathrm{P}<0.05)$. Since this chemotherapy regimen had a longer instillation time (about $48 \mathrm{~h}$ ), there is some clinical practical significance of this statistical difference. Taking the above results together, when using the EPOCH protocol, imported epirubicin is recommended, and should be used as an intravenous infusion together with etoposide and vindesine diluted in $500 \mathrm{~mL}$ of normal saline solution. This mixed liquid character is stable and less irritating at room temperature, which is suitable for clinical practical applications. While central venous infusion is recommended to reduce the possibility of peripheral vascular irritancy and extravasation, in cases involving prolonged infusion, patients should be monitored for possible adverse effects such as granulocytopenia, gastrointestinal reactions, mucositis, cardiac toxicity, and phlebitis, which may be managed symptomatically as necessary to ensure patient safety.

\section{Acknowledgments}

Funding: None.

\section{Footnote}

Data Sharing Statement: Available at https://dx.doi. org/10.21037/tcr-21-1819

Conflicts of Interest: All authors have completed the ICMJE uniform disclosure form (available at https://dx.doi. org/10.21037/tcr-21-1819). The authors have no conflicts of interest to declare.

Etbical Statement: The authors are accountable for all aspects of the work in ensuring that questions related to the accuracy or integrity of any part of the work are appropriately investigated and resolved.

Open Access Statement: This is an Open Access article distributed in accordance with the Creative Commons Attribution-NonCommercial-NoDerivs 4.0 International License (CC BY-NC-ND 4.0), which permits the noncommercial replication and distribution of the article with the strict proviso that no changes or edits are made and the original work is properly cited (including links to both the formal publication through the relevant DOI and the license). See: https://creativecommons.org/licenses/by-nc-nd/4.0/.

\section{References}

1. Zelenetz AD, Gordon LI, Abramson JS, et al. NCCN Guidelines Insights: B-Cell Lymphomas, Version 3.2019. J Natl Compr Canc Netw 2019;17:650-61.

2. Wilson WH, Bryant G, Bates S, et al. EPOCH chemotherapy: toxicity and efficacy in relapsed and refractory non-Hodgkin's lymphoma. J Clin Oncol 1993;11:1573-82.

3. Wilson WH, Dunleavy K, Pittaluga S, et al. Phase II study of dose-adjusted EPOCH and rituximab in untreated diffuse large B-cell lymphoma with analysis of germinal center and post-germinal center biomarkers. J Clin Oncol 2008;26:2717-24.

4. Lu R, Lin Q, Chen S, Ye X. Chemotherapy-induced thrombocytopenia and platelet transfusion in patients with diffuse large B-cell lymphoma. Transl Cancer Res 2020;9:1640-51.

5. Giulino-Roth L, O'Donohue T, Chen Z, et al. Outcomes 
of adults and children with primary mediastinal B-cell lymphoma treated with dose-adjusted EPOCH-R. Br J Haematol 2017;179:739-47.

6. Cabanillas F, Shah B. Advances in Diagnosis and Management of Diffuse Large B-cell Lymphoma. Clin Lymphoma Myeloma Leuk 2017;17:783-96.

7. Bartlett NL, Wilson WH, Jung SH, et al. Dose-Adjusted EPOCH-R Compared With R-CHOP as Frontline Therapy for Diffuse Large B-Cell Lymphoma: Clinical Outcomes of the Phase III Intergroup Trial Alliance/ CALGB 50303. J Clin Oncol 2019;37:1790-9.

8. Bayssas M, Gouveia J, de Vassal F, et al. Vindesine: a new vinca alkaloid. Recent Results Cancer Res 1980;74:91-7.

9. Lahtinen R, Kuikka J, Nousiainen T, et al. Cardiotoxicity of epirubicin and doxorubicin: a double-blind randomized study. Eur J Haematol 1991;46:301-5.

10. Li J, Yao C, Xu Y, et al. In vitro compatibility and stability of admixtures containing etoposide, epirubicin hydrochloride and vindesine sulphate in a single infusion bag. J Clin Pharm Ther 2019;44:875-82.

11. Manrique-Rodríguez S, Heras-Hidalgo I, Pernia-López MS, et al. Standardization and Chemical Characterization of Intravenous Therapy in Adult Patients: A Step Further in Medication Safety [published correction appears in Drugs R D. 2021 Jun;21(2):239-265]. Drugs R D 2021;21:39-64.

(English Language Editor: B. Draper)

Cite this article as: Bi P, Xu W, Li L, Li X, Hu X, Yin Y, Li J. Stability study of the compatibility of three chemotherapeutic agents in a mixture solution of different kinds of vehicles in the EPOCH chemotherapy scheme. Transl Cancer Res 2021;10(11):4829-4837. doi: 10.21037/tcr-21-1819 